\title{
Effects of xanthan gum on atomization and deposition characteristics in water and Silwet 408 aqueous solution
}

\author{
Shilin Wang ${ }^{1}$, Xiongkui He ${ }^{1 *}$, Jianli Song ${ }^{1}$, Shuangshuang Wang ${ }^{2}$, Xiaoming $\mathrm{Jia}^{3}$, Yun Ling ${ }^{1}$ \\ (1. Center for Chemicals Application Technology (CCAT), College of Science, China Agricultural University, Beijing 100193, China; \\ 2. College of Engineering, Huazhong Agricultural University, Wuhan 430070, China; \\ 3. College of Engineering, China Agricultural University, Beijing 100083, China)
}

\begin{abstract}
In order to investigate the effects of viscosity on spray formation and utilization of pesticide, different concentrations of xanthan gum (XG) were added into water and $0.1 \%$ Silwet 408 aqueous solution. Droplet size, relative span (RS), fan angle, length of breakup and maximum retention (Rm) were measured with the LU120-02 nozzle spraying under the pressure of 0.3 $\mathrm{MPa}$. The dynamic spreading of the different solutions on maize leaves was tested using a $5 \mu \mathrm{L}$ micro-injector. The results showed: VMD, RS, length of breakup and Rm went up as the increasing of XG concentration in the range of $0-0.5 \%$ with the same solution, while the fan angle of nozzle and spreading area on maize leaf showed the opposite tendency. Silwet 408 could reduce the surface tension of liquid, which could alter the dominant mode of spray formation and lead to earlier sheet breakup, especially in low viscosity solutions. Under the same concentration of XG the addition of Silwet 408 could reduce the RS of drop size spectrum but has no effect on VMD or fan angle. In water solution, there was no difference with different concentrations of $\mathrm{XG}$ in the spreading time on maize leaf. Besides, in the $0.1 \%$ Silwet 408 aqueous solution, the spraying time and area were several-fold of that in water with same XG concentration. Moreover, with the same XG concentration, the smaller surface tension liquid indicated lower $\mathrm{Rm}$, and the difference was magnified as the concentration increases. This work has demonstrated that initial spray characteristics such as droplet size and RS, fan angle, length of breakup, Rm and spreading area can vary depending on the viscosity of spray liquids. Therefore, by transforming the viscosity of the spray liquid to adjust the droplet spectrum to reduce drift, increasing the $\mathrm{Rm}$ and spreading area to improve liquid utilization and reduce the usage of pesticides.
\end{abstract}

Keywords: atomization, xanthan gum, spray, droplet size, breakup length, dynamic spreading

DOI: $10.25165 /$ j.ijabe.20181103.3802

Citation: Wang S L, He X K, Song J L, Wang S S, Jia X M, Ling Y. Effects of xanthan gum on atomization and deposition characteristics in water and Silwet 408 aqueous solution. Int J Agric \& Biol Eng, 2018; 11(3): 29-34.

\section{Introduction}

Pesticides play an important role in optimizing yields ${ }^{[1]}$, and pesticide application is an integral part of modern agriculture and contributes to the productivity and the quality of cultivated crops ${ }^{[2]}$. Spray as one of the most common forms of pesticide application, researching the process of spray liquid atomization, deposition and spreading characteristics is of great significance to reducing the pesticides usage, improving utilization ratio of pesticides and minimizing environmental contamination. The process from spraying to playing biological efficacy for pesticide is very complicated, including atomization, impaction, retention, deposition formation and biological effect. Atomization plays an

\section{Received date: 2017-09-12 Accepted date: 2018-01-23}

Biographies: Shilin Wang, PhD candidate, research interests: crop protection machinery and pesticide application techniques, Email: shilinag@163.com; Jianli Song, PhD, Associate Professor, research interests: crop protection machinery and pesticide application techniques, Email: songjianli170@163.com; Shuangshuang Wang, PhD, Lecturer, research interests: the processes of spray atomization and droplet deposition, Email: wangshsh_123@mail.hzau.edu.cn; Xiaoming Jia, Master, research interests: crop protection machinery, Email: 1757673032@qq.com; Yun Ling, PhD, Professor, research interests: synthesis of agrochemicals, Email: lyun@cau.edu.cn;

*Corresponding author: Xiongkui He, $\mathrm{PhD}$, Professor, research interests: crop protection machinery and pesticide application techniques. Centre for Chemicals Application Technology (CCAT), China Agricultural University, No.2, Yuanmingyuan West Road, Haidian District, Beijing 100193, China. Email: xiongkui@cau.edu.cn. important role in the process, and it has a great influence on deposition of spray liquids ${ }^{[3-5]}$.

Several papers related to atomization and deposition characteristics of spraying liquid have been published in the past few years. The main initial atomization characteristics are droplet size, droplet velocity, spray sheet and fan angle. Atomization characteristics were influenced by nozzle structure (such as hollow cone, flat fan and air induction) and spray fluid properties ${ }^{[6]}$. Nuyttens et al. ${ }^{[7]}$ have demonstrated that the nozzle type, size of the orifice and pressure affect on the droplet size and velocity spectra. Initial spray characteristics such as droplet size and velocity, liquid density, fan angle and included air are variable depending on nozzle design, operating parameters and spray formulations ${ }^{[8]}$. Other studies also found that in the progress of atomization nozzle structure have significant effect on droplet size and velocity, length of breakup and fan angle ${ }^{[9-14]}$. Technically, scholars studied the effect of spray liquid properties on atomization in the early 1960s. It is well known that spray atomization is greatly influenced by the physical properties of spray liquids such as extensional and shear viscosity, dynamic surface tension and the presence of emulsion droplet ${ }^{[15,16]}$. Bulter Ellis and Mllier investigated the effects of surface tension of surfactant solutions and formulation on spray characteristics produced by hydraulic nozzles used for pesticide application ${ }^{[17-19]}$. Among the physical properties of spray liquid, surface tension is paramount. Cloeter and Qin tested the atomizing progress of water and oil-in-water emulsions, they revealed oil phase in the form of emulsions can 
shorten the length of spray sheet and enlarge the droplet size ${ }^{[20]}$. A reduction of surface tension in a pure liquid results in an increase in the growth rate in instabilities, ultimately leading to earlier sheet breakup ${ }^{[6,21]}$. However, it has been shown that surfactant solutions, which also reduce surface tension, can cause delayed breakup $^{[17]}$. The atomized droplets size, velocity and spray liquids physical properties have great influence on the deposition status. Droplet size, droplet spectrum and direction of motion significantly influence the result of impaction on target, so they are the principal factors to decide the amount of deposition ${ }^{[22-28]}$. In addition, adding adjuvants in the spray liquid can increase the amount of the deposition $^{[29,30]}$.

Accompanied by the utilization rate of pesticide improvement and pesticide application zero growth in 2020 which called by Ministry of Agriculture of the People's Republic of China, low volume (LV) and ultra-low volume (ULV) pesticide application is becoming popular. However, pesticides at LV and ULV should be diluted by 5 to 10 times. Compared to the medium volume (MV) and high volume (HV) spray, viscosity must be taken into account for the influence of atomization and deposition in LV and ULV spray. Many studies paid attention to the surface tension and formulations of spray liquids, while few studies focused on the breakup of spray sheet of viscoelastic fluid ${ }^{[31-33]}$. Therefore, investigating the effects of viscosity on atomization and deposition characteristics of spraying liquid is necessary to raise the utilization rate of pesticide for LV and ULV spray. Xanthan gum, produced by the aerobic fermentation of Xanthomonascampestris, is an extracellular hetero-polysaccharide ${ }^{[34]}$. For its excellent rheological properties, xanthan gum is used as thickening, suspending and stabilizing agent in many areas, such as oil drilling, paint, textile, printing, ceramics, food industry and pesticide manufacture, etc. ${ }^{[35]}$. Xanthan gum is also widely used in pesticide manufacture, as thickener added into aqueous suspension concentrate (SC), suspo-emulsion (SE) and oil in water emulsion (EW) to increase the stability of the dispersion medium.

This study firstly investigated the effects of different liquids on spray formation mechanisms, then measured the maximum retention and dynamic spreading with different concentrations of Xanthan gum. This paper aimed to establish an auxiliary for pesticide atomization and deposition, and to build a guideline for pesticide application and improve the utilization rate of pesticide.

\section{Materials and methods}

Organic silicone surfactant Silwet 408 is a spray adjuvant to reduce the surface tension of spray solution. Xanthan gum (XG) was added into water and $0.1 \%$ Silwet 408 aqueous solution to change the viscosity of spray solutions. The detail concentrations of XG were $0.0 \%, 0.05 \%, 0.10 \%, 0.20 \%, 0.30 \%$ and $0.50 \%$ in mass fractions. Therefore, 12 spray solutions would be tested in total.

\subsection{Spray control system}

The schematic diagram of spray control system used in this experiment is shown in Figure 1. The high-pressure gas in the air compressor could be delivered into the hermetically-sealed tank through the gas tube. When the switch of liquid tube is opened, the spray liquid in the tank could be transported along the liquid tube to the nozzle under the pressure of high pressure gas. In addition to the switch, a pressure regulating valve was also installed on the tube to adjust and stabilize the spray pressure. Moreover, a pressure gauge was assembled near the nozzle, which could accurately visualize the spray pressure during spraying.

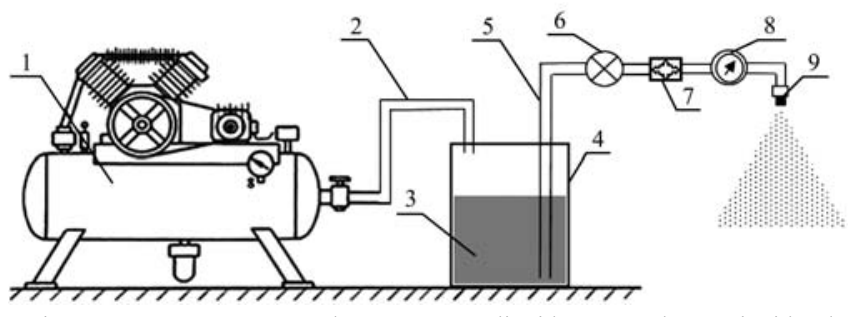

1.Air compressor 2. Gas tube 3. Spray liquid 4. Tank 5. Liquid tube 6. Switch 7. Pressure regulating valve 8 . Pressure gauge 9. Nozzle

Figure 1 Schematic diagram of spray control system

\subsection{Physical properties of spray liquids}

Shear and extensional viscosity of spray solutions were measured by DV2T touch screen viscometer from Brookfield with SC4-31 spindle. Determining the viscosity and shear stress from 10 to 200 revolutions per minute (rpm) under $(25 \pm 1)^{\circ} \mathrm{C}$, the interval of revolution speed was $10 \mathrm{r} / \mathrm{min}$ and measuring one minute at each speed. The surface tension of spray solution was tested using JYW-200A automatic interfacial tension meter. Each measurement was repeated three times.

\subsection{Atomization characteristics}

A standard flat fan nozzle LU120-02 (Lechler GmbH) was selected to spray with a pressure of $0.3 \mathrm{MPa}$. Droplet size distribution was measured with a laser particle size analyzer (Mastersizer 2000, Marvern, UK) by scanning the complete cross-sectional area of the spray at the distance of $500 \mathrm{~mm}$ below the nozzle. Three replicate measurements were made for each spray solution. The data were analyzed to determine the volume median diameter (VMD) and particle relative span (RS) of the spray. RS represents the uniformity of the atomized droplet, and the smaller the RS is, the more uniform is the atomization. The RS was calculated with Equation (1). Dv0.1 is the diameter at which ten percent of the volume of the droplets is contained in droplets at or below that diameter. In the same way, volume medium diameter (VMD) is the diameter at 50 percent, and Dv0.9 is the diameter at 90 percent. In the paper, VMD is on behalf of the statistical droplet size.

$$
R S=\frac{D v 0.9-D v 0.1}{V M D}
$$

High-speed photography (Lighting RTDTM, DRS Technologies, USA) was used to record the structure of liquid film, and the length of breakup defined as Cloeter et al. ${ }^{[36]}$. The high-speed photography was set as follows: 5000 frames per second, shutter speed of $1 / 80000$ s. Keeping the output photography in the document with JPG form, and then measuring the length of breakup and spray angle by image processing software. An image analysis program (ImageJ, USA) was used to measure the fan angle and length of breakup. ImageJ is a public domain Java image processing program inspired by National Institutes of Health. It can read many image formats including TIFF, GIF, JPEG, BMP, DICOM, FITS and "raw". The area, distance, angles and other parameters from the image read by ImageJ could be calculated of measured. Fan angle was taken as the angle between two lines manually along the outer limits of the spray sheet ${ }^{[8]}$. Length of breakup or spray angle in the same treatment was averaged by 30 images, and the standard deviation (bias showed in tables and figures) was also calculated.

\subsection{Deposition and dynamic spreading}

Maize leaf was selected as target for deposition and dynamic spreading test. The critical surface tension of the maize leave determined by graphing method of Zisman ${ }^{[37]}$ is about $47.8 \mathrm{mN} / \mathrm{m}$. 
In the progress of spraying, there is a certain limit to the retention of liquid on leaves. When this limit is exceeded, as a result the loss of pesticide will become inevitably, and the stable deposition after run-off is maximum retention $(R m)$. Therefore, research on the $R m$ of spray liquid has important significance for guiding pesticide application and avoiding pesticide run-off. The determination of $R m$ was referenced to Yuan's method ${ }^{[38]}$. Precision electronic balance was connected to the computer with data line to record the changes of weight readings in balance with the aid of SSCOM software. Under the pressure of $0.3 \mathrm{MPa}$, LU120-02 nozzle was used to determine the $R m$ when the maize leaves were parallel and at a 45-degree angle with the horizontal, respectively. Figure 2 shows the curve of weight displayed on electronic balance about $0.05 \%$ XG in water sprayed by LU120-02 nozzle. Stopped spray at the right time that weight value began to decrease, and waited for a while till the display became stable. The ratio of stable display and leaf area was $R m$ in unit area. The dynamic spreading process of each droplet generated from a $5 \mu \mathrm{L}$ micro-injector on the horizontal maize leaf was captured by the high-speed photograph system at $5 \mathrm{fps}$, then the dynamic spreading area was calculated by the image processing software imageJ from each frame.

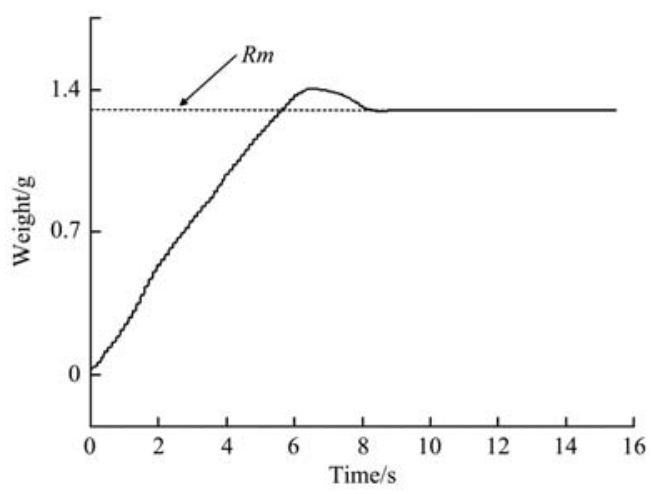

Figure 2 Weight curve of $0.05 \% \mathrm{XG}$ in water

\section{Results}

\subsection{Physical properties of spray liquids}

Table 1 presents the surface tension measurements for all tested solutions. Surface tension reduced greatly when Silwet 408 was added, and XG could reduce surface tension of liquids to some extent. However, surface tension of solutions showed an increasing tendency for both the water and the $0.1 \%$ Silwet 408 aqueous solution when the fraction of $\mathrm{XG}$ was above $0.2 \%$.

Table 1 Surface tension of water and $0.1 \%$ Silwet 408 aqueous solution with various concentrations of $\mathrm{XG}$

$\mathrm{mN} / \mathrm{m}$

\begin{tabular}{ccc}
\hline \multirow{2}{*}{ XG fraction/\% } & \multicolumn{2}{c}{ Solvent } \\
\cline { 2 - 3 } & Water & Water $+0.1 \%$ Silwet408 \\
\hline 0 & $71.21 \pm 0.02$ & $19.66 \pm 0.49$ \\
0.05 & $51.87 \pm 0.13$ & $18.86 \pm 0.09$ \\
0.10 & $52.62 \pm 0.59$ & $19.26 \pm 0.59$ \\
0.20 & $51.93 \pm 0.37$ & $19.74 \pm 0.08$ \\
0.30 & $59.90 \pm 0.12$ & $20.41 \pm 0.67$ \\
0.50 & $61.97 \pm 1.12$ & $22.31 \pm 0.10$ \\
\hline
\end{tabular}

Figure 3 shows the rheological behavior of $\mathrm{XG}$ solutions in water and Sliwet 408 aqueous solution. The result indicated that under certain experimental conditions, the apparent viscosity of solution increased distinctly with the increasing of $\mathrm{XG}$ concentration. XG solutions enhanced the viscosity greatly and exhibited a pronounced shear-thinning behavior, in the same way the results of XG in the Silwet 408 solution were very similar with that in water. With the same XG concentration, there was no significant difference of viscosity between water and $0.1 \%$ Silwet 408 solution, while the surface tensions show in Table 1 of water solutions were significantly greater than that of $0.1 \%$ Silwet 408 solutions.

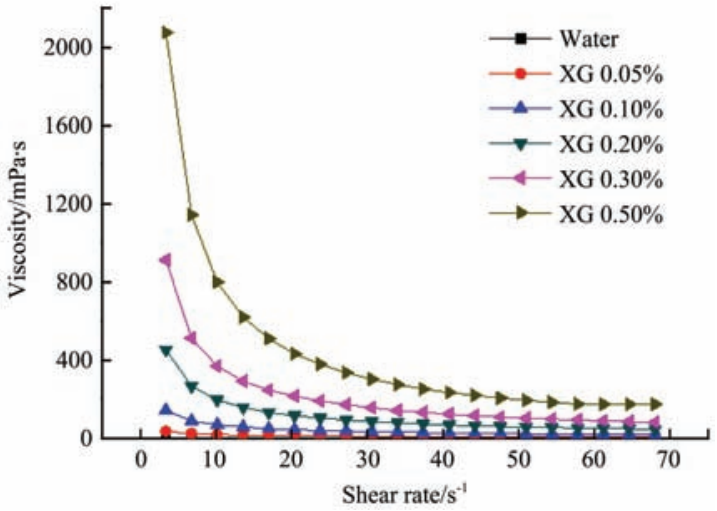

a

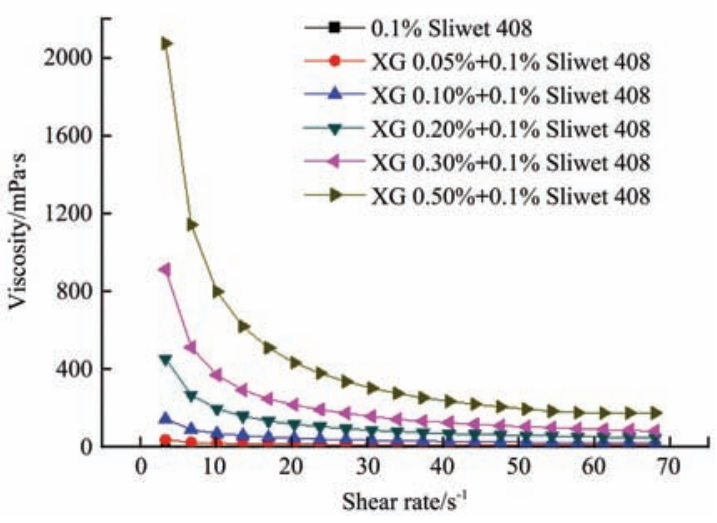

$\mathrm{b}$

Figure 3 Rheological behavior of XG solutions in water (a) and Sliwet 408 aqueous solution (b)

\subsection{Atomization characteristics}

\subsubsection{Droplet size}

The importance of drop size spectrum has been known since a long time ago, and it was known that the adjuvant could have a significant effect upon droplet size in agricultural sprays ${ }^{[17,39]}$. The average VMDs and RSs of drop size spectrum for different concentration of $\mathrm{XG}$ in water and $0.1 \%$ Silwet 408 aqueous solutions are shown in Figure 4 and Figure 5, respectively. As shown in Figure 4, VMDs increased with the increase of viscosity for both water and the Silwet 408 aqueous solution. Overall, when the concentration of XG was under $0.3 \%$, VMDs were mainly affected by viscosity, and were little relation with surface tension. However, the VMD of Silwet 408 was larger than water when the concentration of XG was $0.5 \%$. When there was no XG, the VMD of $0.1 \%$ Silwet 408 was smaller than that of pure water, which was consistent with the results of M.C. Butler Ellis ${ }^{[19]}$. When the concentration of XG was $0 \%$, VMDs of water and Silwet 408 solution were 153.2 and $164.0 \mu \mathrm{m}$, respectively, while when the concentration was $0.5 \%$ they reached up to 306.6 and $369.8 \mu \mathrm{m}$, respectively. In Figure 5, the RS of drop size spectrum increase as XG concentration increased both in water and $0.1 \%$ Silwet 408 solutions. With the same concentration of $\mathrm{XG}$ the addition of Silwet 408 could reduce RS, which could lead to better atomization 
and produce more uniform droplets. For pure water and $0.1 \%$ Silwet 408 solution the RSs were 1.48 and 1.32, respectively. When the concentration of XG was $0.5 \%$, the RSs of water and Silwet 408 were 1.97 and 1.75 .

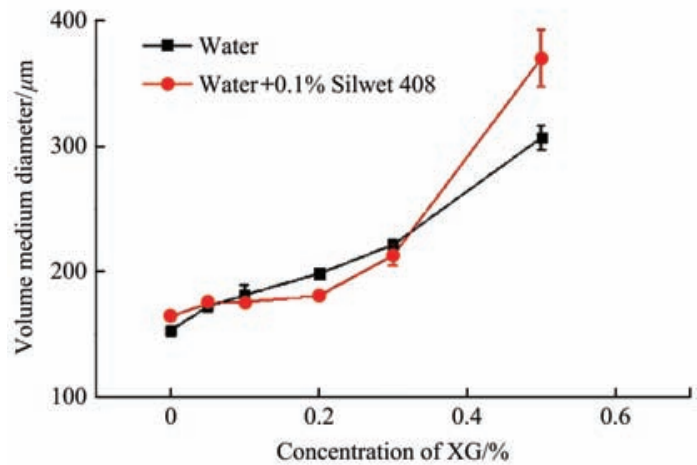

Figure 4 VMDs for different concentration of $\mathrm{XG}$ in water and $0.1 \%$ Silwet 408 solutions

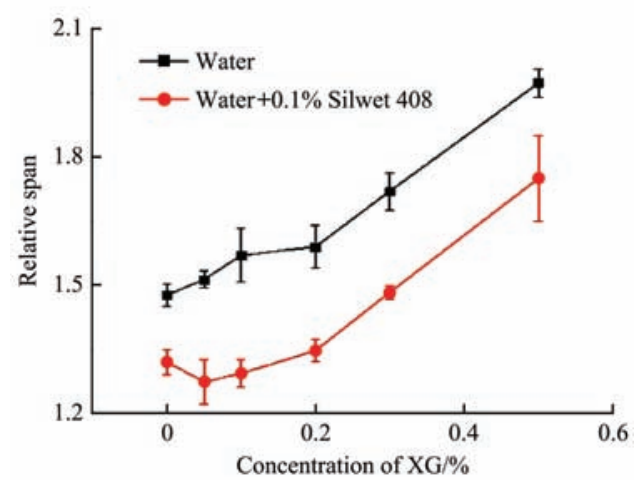

Figure 5 Relative span of different concentrations of XG in water and $0.1 \%$ Silwet 408 aqueous solutions

\subsubsection{Fan angle}

The fan angles of the spray sheet generated from LU120-02 with a pressure of $0.3 \mathrm{MPa}$ for different concentrations of $\mathrm{XG}$ are shown in table 2. The standard fan angle of LU120-02 was $120^{\circ}$, all the results in the table were smaller than it. In pure water and $0.1 \%$ Silwet 408 aqueous solution the fan angles were $117.43^{\circ}$ and $118.52^{\circ}$, which were pretty close to the standard value. The fan angles decreased with the concentration of XG increased. When the concentration of $\mathrm{XG}$ was $0.5 \%$, the fan angle in water and $0.1 \%$ Silwet 408 aqueous solutions were 96.34 and $96.40^{\circ}$, which were much lower than the standard angle. Under the same $\mathrm{XG}$ concentrations there was no difference between the results of water and Silwet 408, as a result, the Silwet 408 did not have a significant influence on fan angle.

Table 2 Fan angle of different concentrations of XG in water and $0.1 \%$ Silwet 408 aqueous solutions

\begin{tabular}{|c|c|c|c|c|c|c|}
\hline \multirow{2}{*}{$\begin{array}{c}\text { Spray } \\
\text { solutions }\end{array}$} & \multicolumn{6}{|c|}{$\mathrm{XG}$ fraction $/ \%$} \\
\hline & 0.00 & 0.05 & 0.10 & 0.20 & 0.30 & 0.50 \\
\hline water & $\begin{array}{c}117.43 \pm \\
3.32^{\circ}\end{array}$ & $\begin{array}{c}107.90^{ \pm} \\
2.24^{\circ}\end{array}$ & $\begin{array}{c}104.26 \pm \\
1.62^{\circ}\end{array}$ & $\begin{array}{c}101.98 \pm \\
1.04^{\circ}\end{array}$ & $\begin{array}{c}98.36 \pm \\
1.73^{\circ}\end{array}$ & $\begin{array}{c}96.34 \pm \\
1.28^{\circ}\end{array}$ \\
\hline $\begin{array}{c}0.1 \% \\
\text { Silwet408 }\end{array}$ & $\begin{array}{c}118.52 \pm \\
2.43^{\circ}\end{array}$ & $\begin{array}{c}106.64 \pm \\
1.03^{\circ}\end{array}$ & $\begin{array}{c}104.34 \pm \\
1.45^{\circ}\end{array}$ & $\begin{array}{c}101.96 \pm \\
0.95^{\circ}\end{array}$ & $\begin{array}{c}98.53 \pm \\
1.70^{\circ}\end{array}$ & $\begin{array}{c}96.40 \pm \\
1.19^{\circ}\end{array}$ \\
\hline
\end{tabular}

\subsubsection{Breakup Length}

Figure 6 shows the relationship between breakup length of sheet and XG concentrations. Both in water and in Silwet 408 solutions, the higher the $\mathrm{XG}$ concentration was, the longer the length of breakup would be. Similarly, VMDs of droplets followed the same tendency, which was consistent with the result of $\mathrm{Xie}^{[40]}$. The liquid sheet breakup mechanism was affected when XG added, since the structure of liquid sheet changed dramatically. The reason for the increase of breakup length was high viscosity moved the position of disintegration away from the nozzle by damping out the wavelike oscillations of liquid sheet, allowing the sheet to continue for longer before breakup occurred ${ }^{[17]}$.

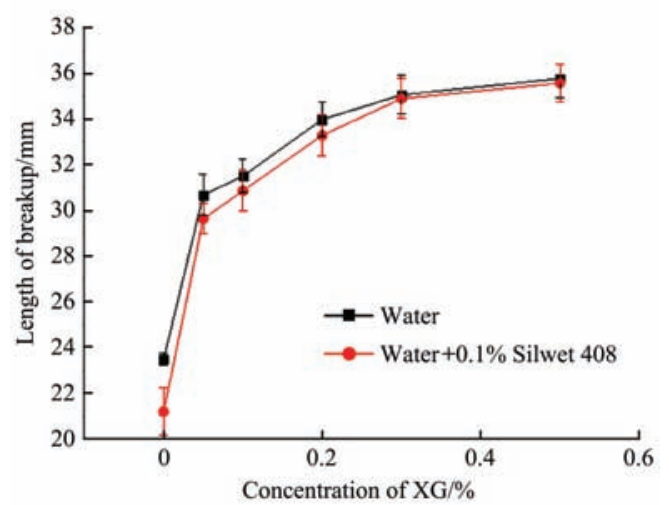

Figure 6 Breakup length of different concentrations of XG in water and $0.1 \%$ Silwet 408 solution

Silwet 408 could alter the dominant mode of spray formation. The images of liquid sheet in pure water and $0.1 \%$ Silwet 408 aqueous solution are shown in Figure $7 \mathrm{a}$ and Figure $7 \mathrm{~b}$, respectively. Compared with Figure $7 \mathrm{a}$, Figure $7 \mathrm{~b}$ shows more perforating on the sheet and the rupture of sheet was much earlier. The addition of Silwet 408 reduced the surface tension of spray liquid, which could make the liquid overcome less surface tension in the progress of atomization. A reduction in surface tension resulted in an increase in instabilities and leaded to earlier sheet breakup, the lengths of breakup in water and Silwet 408 solution were $23.5 \mathrm{~mm}$ and $21.2 \mathrm{~mm}$. The larger the XG concentration was, the less significant the influence of surface tension on the length of breakup. As Figure 7c and Figure 7d show, when the XG concentration was $0.1 \%$, there was little difference in the two images. When the XG concentration was $0.5 \%$, the lengths of breakup in water and Silwet 408 aqueous solutions were $35.8 \mathrm{~mm}$ and $35.6 \mathrm{~mm}$. Actually, atomization is a very complicated process and there are many interacting factors needed to be taken into account to fully explain the effects of spray formation.

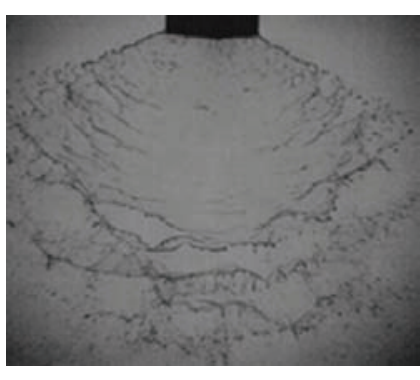

a. Water

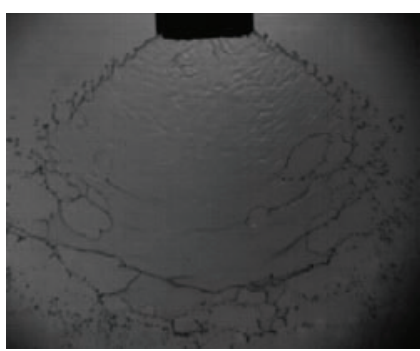

c. $0.1 \% \mathrm{XG}$

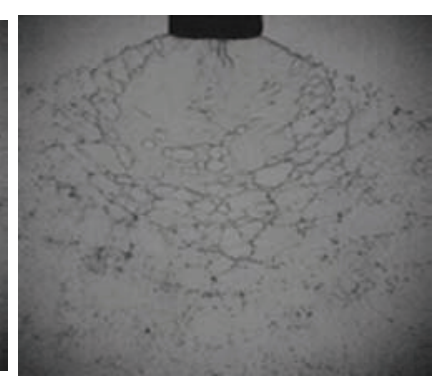

b. Water $+0.1 \%$ Silwet 408

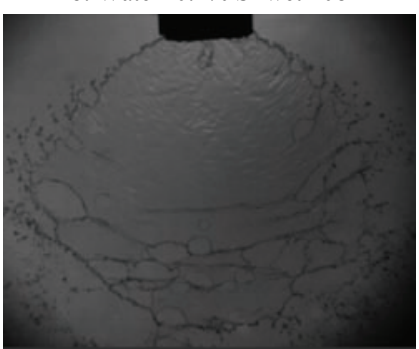

d. Water+ 0.1 Silwet $408+0.1 \%$ XG
Figure 7 Images of liquid sheet in different solutions 


\subsection{Deposition and dynamic spreading}

As can be seen from Figure 8, both on the horizontal and on the $45^{\circ}$ targets the Rms increased with increasing concentration of XG. Addition of XG increased the adhesion property of spray liquid on the target. The Rm of the same spray solution on the horizontal target was about 5 times of that on the 45 degree target. The addition of Silwet 408 reduced the surface tension of solutions, improved the spreading performance and fluidity of the solutions on the target. Therefore, the Rm of the Silwet 408 aqueous solutions with $\mathrm{XG}$ were less than that of the water solutions with $\mathrm{XG}$.

A good spreading effect is conductive to improve the coverage of spray liquid, which plays an important role in pesticide efficacy. Figure 9 shows the dynamic spreading of different $\mathrm{XG}$ concentrations in water and $0.1 \%$ Silwet 408 aqueous solutions on maize leaf. The eventually spreading area of liquids showed a

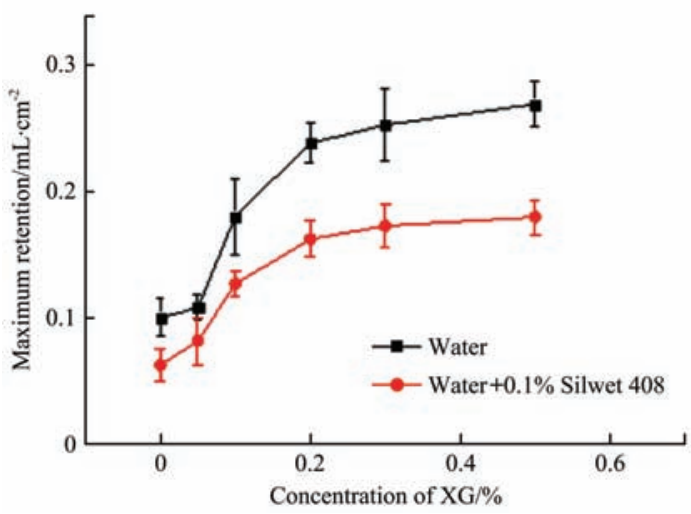

a. Horizontal

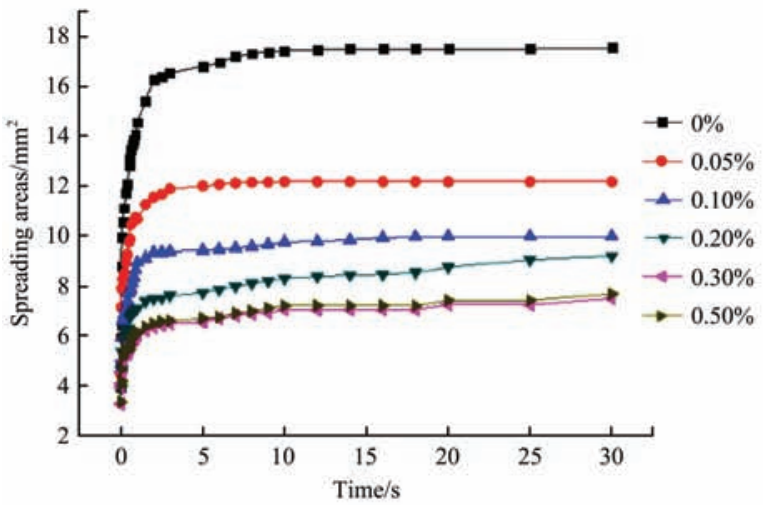

a. Water negative linear correlation with the concentration of XG. In pure water, the time to achieve the largest spreading area for different XG concentrations was very similar, which was about $2.5 \mathrm{~s}$. In the same way, the time of which in $0.1 \%$ Silwet 408 aqueous solution was different. The time required for the largest area decreased with the increasing of XG concentration. When none $\mathrm{XG}$ was added the time to achieve largest area was nearly $20 \mathrm{~s}$, and with $0.50 \% \mathrm{XG}$ added the time was less than $2 \mathrm{~s}$ in $0.1 \%$ Silwet 408 aqueous solution. The addition of Silwet 408 greatly increased the spreading area of liquids on maize leaf, as a result the spreading area of Silwet 408 solutions were several-fold of that in water with the same XG concentration. On top of that, the effect of deposition and spreading area on control effect of pesticide should also be taken into account when changing properties of spray liquid such as viscosity or surface tension.

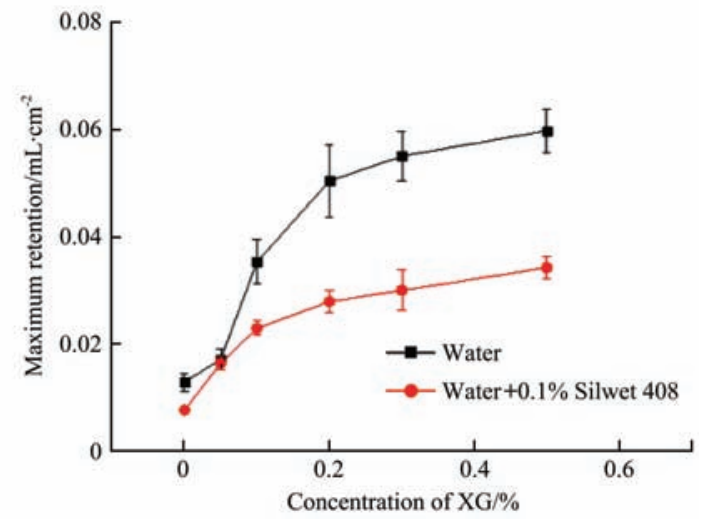

b. $45^{\circ}$

igure $8 \mathrm{Rm}$ for different $\mathrm{XG}$ concentrations in different solutions

Figure 9 Dynamic spreading for different XG concentrations in water and $0.1 \%$ Silwet 408 aqueous solutions

\section{Conclusions}

The atomization and deposition characteristics of XG added in water and $0.1 \%$ Silwet 408 solutions were studied. Droplet size, $\mathrm{RS}$, fan angle, length of breakup and $\mathrm{Rm}$ were tested with LU120-02 nozzle spraying at $0.3 \mathrm{MPa}$. The dynamic spreading process of the different solutions on maize leaves was tested using a 5 microliter micro-injector. The conclusions include:

(1) In the same solution, VMD, RS, length of breakup and $\mathrm{Rm}$ went up as the increasing of XG concentration in the range from $0 \%$ to $0.5 \%$, while the fan angle of nozzle and spreading area on maize leaf showed the opposite tendency.

(2) Silwet 408 could reduce the surface tension of liquid, and further to alter the dominant mode of spray formation and lead to

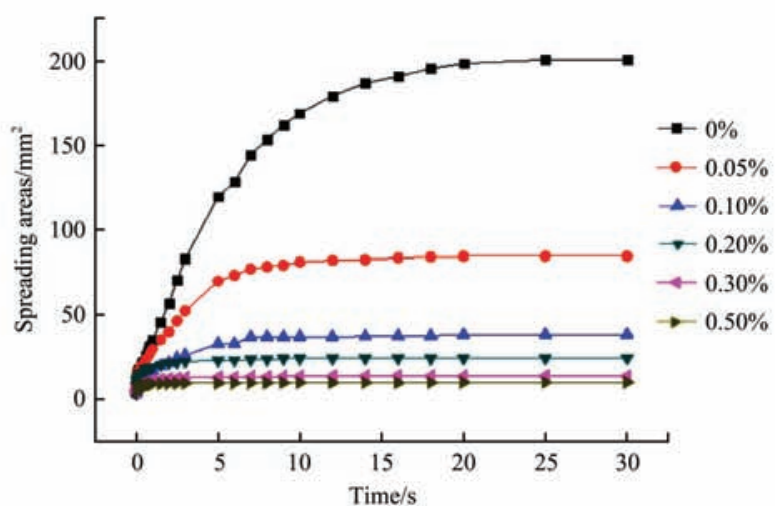

b. Water $+0.1 \%$ Silwet 408 earlier sheet breakup, especially in low viscosity solutions. Under the same concentration of XG the addition of Silwet 408 could reduce the RS of drop size spectrum but had no effect on VMD or fan angle.

(3) In water solution, there was no difference with different concentration of XG in the spreading time on maize leaf. Besides, in the $0.1 \%$ Silwet 408 aqueous solution, the spraying time and area were several-fold of that in water with same XG concentration. Moreover, with the same XG concentration, the smaller surface tension liquid indicated lower $\mathrm{Rm}$, and the difference was magnified as the concentration increases.

\section{Acknowledgements}

This work was financially supported by the Special Fund for 
Agro-scientific Research in the Public Interest (No. 201503130), Joint Sino-German Research Project Application (No. 31761133019), and the Fundamental Research Funds for the Central Universities (No. 2662015QD045). The authors are grateful to Prof. Du Fengpei and Dr. Zhao Xin from College of Science, China Agricultural University for providing viscometer.

\section{[References]}

[1] Matthews G A, Bateman R, Miller P. Pesticide Application Methods. John Wiley \& Sons, 2014

[2] Hilz E, Vermeer A W P. Spray drift review: The extent to which a formulation can contribute to spray drift reduction. Crop Protection, 2013; 44: 75-83.

[3] Werner S R L, Jones J R, Paterson A H J, Archer R H, Pearce D L. Droplet impact and spreading: Droplet formulation effects. Chemical Engineering Science, 2007; 62(9): 2336-2345.

[4] Sikalo S, Marengo M, Tropea C, Ganic E N. Analysis of impact of droplets on horizontal surfaces. Experimental Thermal \& Fluid Science, 2002; 25(7): 503-510.

[5] Wang M, Lin F, Ong J Y, Lin S. Dynamic behaviors of droplet impact and spreading-Water on glass and paraffin. Colloids \& Surfaces A: Physicochemical \& Engineering Aspects, 2009; 339(1): 224-231.

[6] Lefebvre A H, McDonell V G. Atomization and sprays. CRC press, 2017.

[7] Nuyttens D, Baetens K, De Schampheleire M, Sonck B. Effect of nozzle type, size and pressure on spray droplet characteristics. Biosystems Engineering, 2007; 97(3): 333-45.

[8] Dorr G J, Hewitt A J, Adkins S W, Hanan J, Zhang H, Noller B. A comparison of initial spray characteristics produced by agricultural nozzles. Crop Protection, 2013; 53: 109-117.

[9] Ellis A, Swan T, Miller P, Waddelow S, Bradley A, Tuck C R. Design factors affecting spray characteristics and drift performance of air induction nozzles. Biosystems Engineering, 2002; 82(3): 289-296.

[10] Sidahmed M M. A theory for predicting the size and velocity of droplets from pressure nozzles. Transactions of the ASAE, 1996; 39(2): 385-391.

[11] Czaczyk Z. Influence of air flow dynamics on droplet size in conditions of air-assisted sprayers. Atomization \& Sprays, 2012; 22(4): 275-282.

[12] Vallet A, Tinet C. Characteristics of droplets from single and twin jet air induction nozzles: A preliminary investigation. Crop Protection, 2013; 48: $63-68$

[13] Fritz B K, Hoffmann W C, Bagley W E, Kruger G R, Czaczyk Z, Henry R $\mathrm{S}$. Measuring droplet size of agricultural spray nozzles-measurement distance and airspeed effects. Atomization \& Sprays, 2014; 24(9): 747-760.

[14] Wang S, Dorr G J, Khashehchi M, He X. Performance of Selected Agricultural Spray Nozzles using Particle Image Velocimetry. Journal of Agricultural Science \& Technology, 2015; 17(3): 601-613.

[15] Hilz E, Vermeer AWP. Spray drift review: The extent to which a formulation can contribute to spray drift reduction. Crop Protection, 2013; 44: 75-83.

[16] Hewitt A J. Spray optimization through application and liquid physical property variables-I. Environment Systems and Decisions, 2008; 28(1): 25-30

[17] Ellis M, Tuck CR, Miller P. The effect of some adjuvants on sprays produced by agricultural flat fan nozzles. Crop Protection, 1997; 16(1): $41-50$.

[18] Miller P, Ellis M. Effects of formulation on spray nozzle performance for applications from ground-based boom sprayers. Crop Protection, 2000; 19(8-10): 609-615.

[19] Ellis M, Tuck CR, Miller P. How surface tension of surfactant solutions influences the characteristics of sprays produced by hydraulic nozzles used for pesticide application. Colloids \& Surfaces A: Physicochemical \&
Engineering Aspects, 2001; 180(3): 267-276.

[20] Qin K, Cloeter M, Tank H. Modeling the Spray Atomization of Emulsion Embedded Agricultural Solutions. Journal of ASTM International, 2010; 7(10): 1-9.

[21] Rangel R H, Sirignano W A. Nonlinear growth of Kelvin-Helmholtz instability: Effect of surface tension and density ratio. Physics of Fluids, 1988; 31(7): 1845-1855.

[22] Deng W, Meng Z J, Chen L P. Measurement Methods of Spray Droplet Size and Velocity. Journal of Agricultural Mechanization Research, 2011; 33(5): 26-30. (in Chinese)

[23] Zhu J W, Shi J, Zhu G N. Influence of Droplet Size and Spray Volume on Retention of Chlorpyrifos on Cabbage Leaves. China Vegetables, 2003; 1(6): 3-5. (in Chinese)

[24] Werner S R L, Jones J R, Paterson A H J, Archer R H, Pearce D L. Droplet impact and spreading: Droplet formulation effects. Chemical Engineering Science, 2007; 62(9): 2336-2345.

[25] Crooks R, Cooper-Whitez J, Boger D V. The role of dynamic surface tension and elasticity on the dynamics of drop impact. Chemical Engineering Science, 2001; 56(19): 5575-5592.

[26] Sikalo S, Marengo M, Tropea C, Ganic E N. Analysis of impact of droplets on horizontal surfaces. Experimental Thermal \& Fluid Science, 2002; 25(7): 503-510.

[27] Bertola V. Effect of polymer additives on the apparent dynamic contact angle of impacting drops. Colloids \& Surfaces A Physicochemical \& Engineering Aspects, 2010; 363(1-3): 135-140.

[28] Wang M, Lin F, Ong J Y, Lin S. Dynamic behaviors of droplet impact and spreading-Water on glass and paraffin. Colloids \& Surfaces A Physicochemical \& Engineering Aspects, 2009; 339(1): 224-231.

[29] Sybranda V Z, Brink J, Calitz F J, Coertze S, Fourie PH. The use of adjuvants to improve spray deposition and Botrytis cinerea control on Chardonnay grapevine leaves. Crop Protection, 2010; 29(1): 58-67.

[30] Garcera C, Molto E, Chueca P. Effect of spray volume of two organophosphate pesticides on coverage and on mortality of California red scale Aonidiella aurantii (Maskell). Crop Protection, 2011; 30(6): 693-697.

[31] Stelter M, Brenn G, Durst F. The influence of viscoelastic fluid properties on spray formation from flat-fan and pressure-swirl atomizers. Atomization \& Sprays, 2002; 12(1-3): 299-327.

[32] Miller E, Gibson B, McWilliams E, Rothstein J P. Collision of viscoelastic jets and the formation of fluid webs. Applied Physics Letters 87, 2005; 014101-1.

[33] Brenn G, Liu ZB, Durst F. Three-dimensional temporal instability of non-Newtonian liquid sheets. Atomization \& Sprays, 2001; 11(1): 49-84.

[34] Psomas S K, Liakopoulou-Kyriakides M, Kyriakidis D A. Optimization study of xanthan gum production using response surface methodology. Biochemical Engineering Journal, 2007; 35(3): 273-280.

[35] Katzbauer B. Properties and applications of xanthan gum. Polymer Degradation \& Stability, 1998; 59(1-3): 81-84.

[36] Cloeter M D, Qin K, Patil P. Planar laser induced fluorescence (PLIF) flow visualization applied to agricultural spray nozzles with sheet disintegration; Influence of an oil-in-water emulsion. ILASS-Americas 22nd Annual Conf. on Liquid Atomization and Spray Systems. Cincinnati, USA, 2010.

[37] Zisman W A. Relation of the equilibrium contact angle to liquid and solid constitution. Advances in Chemistry, 2008; 43: 1-51.

[38] Yuan H, Qi S, Yang D B. Study on the point of run-off and the maximum retention of spray liquid on crop leaves. Chinese Journal of Pesticide Science, 2000; 2(4): 66-71. (in Chinese)

[39] Stainier C, Destain M F, Schiffers B. Effect of the entrained air and initial droplet velocity on the release height parameter of a Gaussian spray drift model. Commun Agric Appl Biol Sci, 2006; 71(2 Pt A): 197-200.

[40] Xie C, He X, Song J. Comparative research of two kinds of flat fan nozzle atomization process. Transactions of the CSAE, 2013; 29(5): 25-30. (in Chinese) 